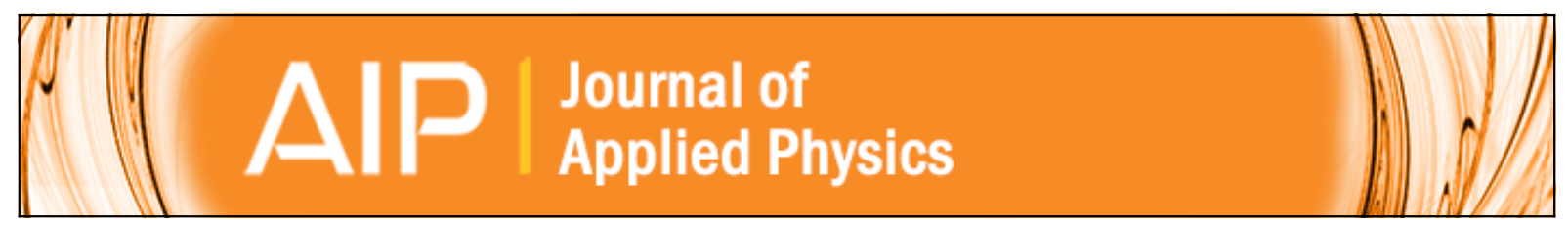

\title{
Effect of spacer layer thickness on magnetic interactions in self-assembled single domain iron nanoparticles
}

Nichole B. Herndon, Sang Ho Oh, Jeremiah T. Abiade, Devdas Pai, Jag Sankar, Stephen J. Pennycook, and Dhananjay Kumar

Citation: Journal of Applied Physics 103, 07 D515 (2008); doi: 10.1063/1.2833309

View online: http://dx.doi.org/10.1063/1.2833309

View Table of Contents: http://scitation.aip.org/content/aip/journal/jap/103/7?ver=pdfcov

Published by the AIP Publishing

\section{Articles you may be interested in}

Facile synthesis of single-phase spherical $\alpha^{\prime \prime}-\mathrm{Fe} 16 \mathrm{~N} 2 / \mathrm{Al} 2 \mathrm{O} 3$ core-shell nanoparticles via a gas-phase method J. Appl. Phys. 113, 164301 (2013); 10.1063/1.4798959

Influence of excess Fe accumulation over the surface of FePt nanoparticles: Structural and magnetic properties J. Appl. Phys. 113, 134303 (2013); 10.1063/1.4796091

Synthesis of self-assembled monodisperse $3 \mathrm{~nm}$ FePd nanoparticles: Phase transition, magnetic study, and surface effect

J. Appl. Phys. 104, 123906 (2008); 10.1063/1.3042259

Composition dependent magnetic properties of iron oxide-polyaniline nanoclusters

J. Appl. Phys. 97, 014311 (2005); 10.1063/1.1829788

Coercivity and remanence in self-assembled FePt nanoparticle arrays

J. Appl. Phys. 93, 7041 (2003); 10.1063/1.1557398

\section{MIT LINCOLN} LABORATORY CAREERS

Discover the satisfaction of innovation and service to the nation
- Space Control

- Air \& Missile Defense

- Communications Systems \& Cyber Security

- Intelligence, Surveillance and

Reconnaissance Systems

$$
\begin{aligned}
& \text { - Advanced } \\
& \text { Electronics } \\
& \text { - Tactical Systems } \\
& \text { - Homeland } \\
& \text { Protection } \\
& \text { - Air Traffic Control }
\end{aligned}
$$

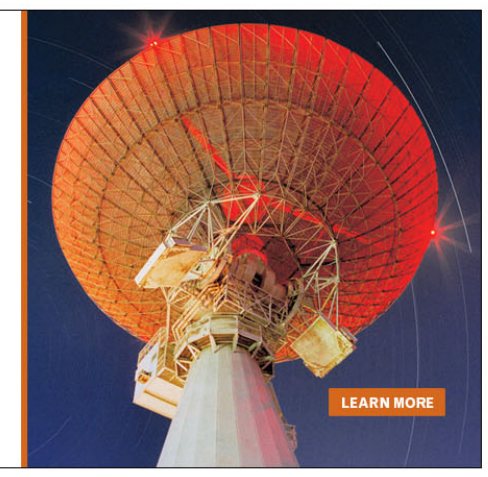




\title{
Effect of spacer layer thickness on magnetic interactions in self-assembled single domain iron nanoparticles
}

\author{
Nichole B. Herndon, ${ }^{1}$ Sang Ho Oh, ${ }^{1,2}$ Jeremiah T. Abiade, ${ }^{3}$ Devdas Pai, ${ }^{1}$ Jag Sankar, ${ }^{1}$ \\ Stephen J. Pennycook, ${ }^{2}$ and Dhananjay Kumar ${ }^{1,2, a)}$ \\ ${ }^{1}$ Center for Advanced Materials and Smart Structures, Department of Mechanical and Chemical \\ Engineering, North Carolina Agricultural and Technical State University, North Carolina 27411, USA \\ ${ }^{2}$ Materials Science and Technology Division, Oak Ridge National Laboratory, Oak Ridge, Tennesse 37831, \\ USA \\ ${ }^{3}$ Department of Materials Science and Engineering and Department of Mechanical Engineering, Virginia \\ Polytechnic Institute and State University, Blacksburg, Virginia 24061, USA
}

(Presented on 9 November 2007; received 13 September 2007; accepted 25 October 2007; published online 29 January 2008)

The magnetic characteristics of iron nanoparticles embedded in an alumina thin film matrix have been studied as a function of spacer layer thickness. Alumina as well as iron nanoparticles were deposited in a multilayered geometry using sequential pulsed laser deposition. The role of spacer layer thickness was investigated by making layered thin film composites with three different spacer layer thicknesses $(6,12$, and $18 \mathrm{~nm})$ with fixed iron particle size of $\sim 13 \mathrm{~nm}$. Intralayer magnetic interactions being the same in each sample, the variation in coercivity and saturation magnetization is attributed to thickness dependent interlayer magnetic interactions of three types: exchange, strong dipolar, and weak dipolar. A thin film composite multilayer structure offers a continuously tunable strength of interparticle dipole-dipole interaction and is thus well suited for studies of the influence of interaction on the magnetic properties of small magnetic particle systems. (C) 2008 American Institute of Physics. [DOI: 10.1063/1.2833309]

Materials consisting of self-assembled nanosized magnetic particles embedded in a host matrix have received considerable attention since they offer the potential to satisfy the critical needs of data storage devices. ${ }^{1-3}$ Magnetic nanoparticles assembled in an insulating matrix can also provide great insight into the physics of magnetic interactions. ${ }^{4}$ Assemblies of small magnetic particles have been synthesized predominantly using chemical processes where interparticle separation is manipulated by controlling the volume fraction of particulate systems in host matrices. ${ }^{5-8}$ Using an exclusive chemical process, however, it is a challenge to fabricate nanoparticle thin film composite in a multilayered geometry which is important for the device applications of nanocomposites. ${ }^{9-12}$ In this paper, we report our investigation on the role of spacer layer thickness on magnetic interaction and resulting magnetic properties of nanoparticles assembled in a three dimensional structure using a pulsed laser deposition (PLD) method.

A multitarget PLD system was used where iron and alumina targets were alternately ablated. The details of PLD process parameters are reported in our previous publications. ${ }^{13,14}$ The thickness of first $\mathrm{Al}_{2} \mathrm{O}_{3}$ layer, which serves as barrier layer was $75 \mathrm{~nm}$, is significantly larger than the thicknesses of $\mathrm{Al}_{2} \mathrm{O}_{3}$ in subsequent layers, where it acts as spacer layer. While the size of Fe nanocrystals was kept fixed in all the samples, the thickness of $\mathrm{Al}_{2} \mathrm{O}_{3}$ layer was varied from sample to sample by varying the number of laser

\footnotetext{
${ }^{a)}$ Author to whom correspondence should be addressed. Electronic mail: dkumar@ncat.edu.
}

pulses impinging on the $\mathrm{A}_{2} \mathrm{O}_{3}$ target. The numbers of alternating layers $\left(\mathrm{Fe}\right.$ and $\mathrm{Al}_{2} \mathrm{O}_{3}$ ) were five.

The size of Fe particles, the exact thickness of the spacer layer, and interparticle separation were investigated by crosssectional scanning transmission electron microscopy (STEM). Shown in Fig. 1(a) is the STEM image of five layered $\mathrm{Fe}-\mathrm{Al}_{2} \mathrm{O}_{3}$ sample prepared using 1500 pulses of laser on $\mathrm{Fe}$ target and 166 pulses on $\mathrm{Al}_{2} \mathrm{O}_{3}$ target. The average Fe particle size is $\sim 13 \pm 5 \mathrm{~nm}$, the average intralayer particle separation is $\sim 3 \mathrm{~nm}$, and the interparticle separation is $\sim 6 \mathrm{~nm}$. Though the majority of particles in one layer are physically separated from the particles in layers above or below it, in some regions, the interparticles are in direct contacts with each other. A similar STEM image of another sample prepared using 500 laser pulses on $\mathrm{Al}_{2} \mathrm{O}_{3}$ target is shown in Fig. 1(b). The number of laser pulses on Fe target was fixed as in the previous sample, i.e., 1500. Clearly, the spacer layer thickness has increased $(\sim 18 \mathrm{~nm})$ and the particles in one layer are well separated from the particles in the other layers. The particle size as well as intralayer particle separation are almost the same as the last sample. As seen in the two insets in Fig. 1, the interface between Fe nanoparticle and the surrounding $\mathrm{Al}_{2} \mathrm{O}_{3}$ matrix in both samples is clean and sharp, indicating the presence of pure metallic $\mathrm{Fe}$ at the surface. Looking at the absolute value of the heat of formation $\left(\Delta H_{f}\right)$ for the most stable iron oxide $(-39.2 \mathrm{kcal} / \mathrm{g}$ atom), one might speculate the formation of an oxide layer on the Fe particle surface more when the matrix surrounding the nanoparticles is an oxide. ${ }^{15,16}$ However, the $\Delta H_{f}$ for iron oxide is almost twice the $\Delta H_{f}$ of aluminum oxide $(-80.2 \mathrm{kcal} / \mathrm{g}$ atom $) .{ }^{15,16}$ The more negative the value of the 

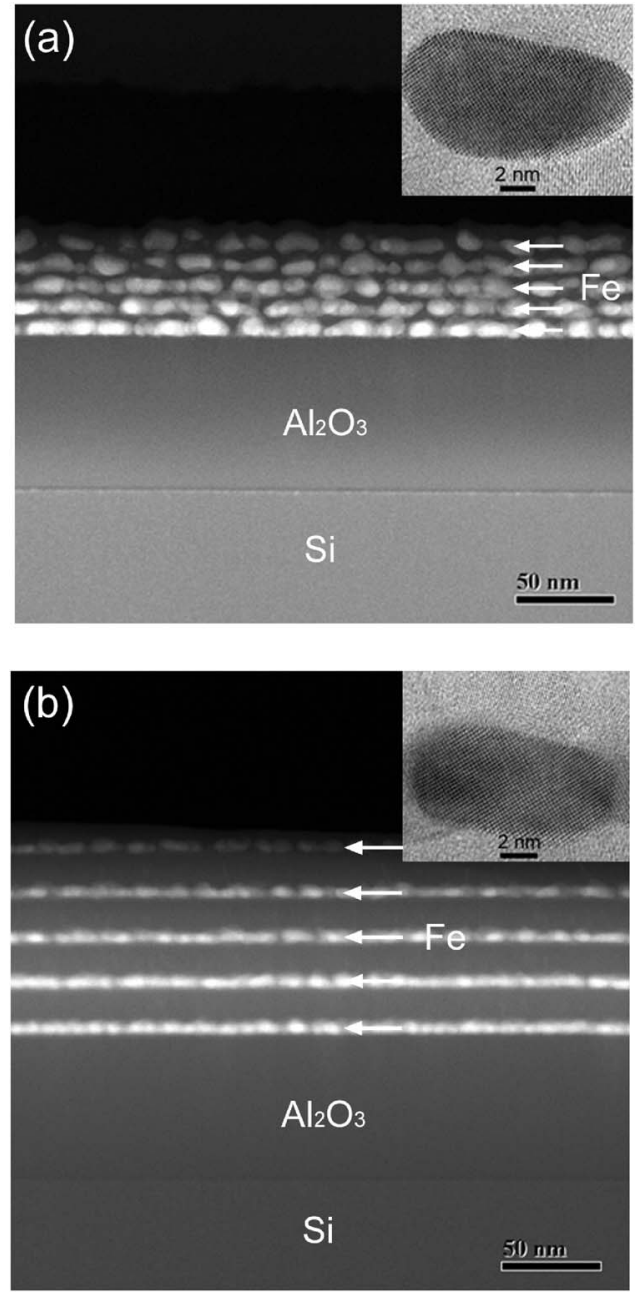

FIG. 1. STEM high angle annular dark-field images of (a) $\mathrm{Fe}-\mathrm{Al}_{2} \mathrm{O}_{3}$ multilayer with $6 \mathrm{~nm}$ thick $\mathrm{Al}_{2} \mathrm{O}_{3}$ spacer layers and (b) $\mathrm{Fe}-\mathrm{Al}_{2} \mathrm{O}_{3}$ multilayer with $18 \mathrm{~nm}$ thick $\mathrm{Al}_{2} \mathrm{O}_{3}$ spacer layers. The insets are STEM bright-field images of single isolated $\mathrm{Fe}$ particles embedded in $\mathrm{Al}_{2} \mathrm{O}_{3}$ spacer layers.

$\Delta H_{f}$, the more strong the element bonds to oxygen. Besides, all the sample fabrications are carried out in high vacuum condition $\left(\sim 10^{-7}\right.$ torr). Our previous atomic level structural characterization study by means of STEM and electron energy loss spectroscopy on nanoparticles of $\mathrm{Ni}$ [which has a similar $\Delta H_{f}$ for its stable oxide $(-28.8 \mathrm{kcal} / \mathrm{g}$ atom) embedded in $\mathrm{A}_{2} \mathrm{O}_{3}$ thin film matrix using the PLD and similar deposition conditions] had proved the absence of any oxide layer on the $\mathrm{Ni}$ nanoparticle surface. ${ }^{14}$ Thus, based on the heat of formation data and the structural characterization information of $\mathrm{Ni}-\mathrm{Al}_{2} \mathrm{O}_{3},{ }^{14}$ it is reasonable to assume that the $\mathrm{Fe}$ nanoparticles in $\mathrm{Al}_{2} \mathrm{O}_{3}$ matrix have very high likelihood to be free from any appreciable oxide dead layer in the present study.

The magnetic properties of $\mathrm{Fe}-\mathrm{Al}_{2} \mathrm{O}_{3}$ systems were measured using a vibrating sample magnetometer interfaced with a physical property measurement system. Figure 2 shows the magnetic moment versus field loops at $10 \mathrm{~K}$ for $\mathrm{Fe}-\mathrm{Al}_{2} \mathrm{O}_{3}$ samples having three different spacer layer thicknesses. The magnetic moment versus field loops were also recorded at several other temperatures between 10 and $300 \mathrm{~K}$ for samples with different spacer layer thicknesses. The re-

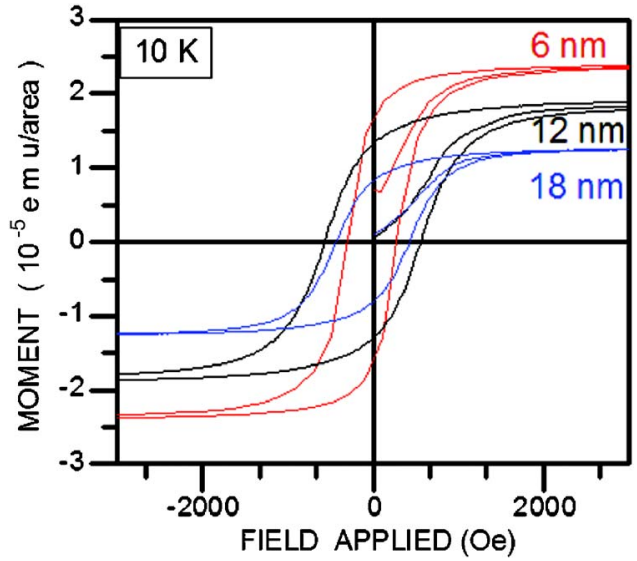

FIG. 2. (Color online) Magnetic moment vs field applied loops at $10 \mathrm{~K}$ for samples with 6,12 , and $18 \mathrm{~nm}$ thick spacer layer $\mathrm{Al}_{2} \mathrm{O}_{3}$.

sults are plotted in Fig. 3 in the form of $H_{c}$ vs $\sqrt{T}$. The coercivity values of the sample with $12 \mathrm{~nm}$ thick $\mathrm{Al}_{2} \mathrm{O}_{3}$ spacer layer are higher than that of the other two samples at all the temperatures. In an assembly of single domain magnetic particles, the magnetic field $\left(H_{c}\right)$ required to reverse their magnetization is given by the equation,

$$
H_{c}=2 K / M_{s}\left[1-\left(T / T_{B}\right)^{1 / 2}\right] \text {, }
$$

where $T_{B}\left(=K V / 25 k_{B}\right.$ for uniaxial anisotropy $)$ is called the blocking temperature where the metastable hysteretic response is lost for a particular observation time. Here, $K$ is the anisotropy constant of the particle material, $V$ is the volume of the particle, and $M_{s}$ is the saturation magnetization. $K V$ is thus the anisotropy energy barrier for the reversal of magnetization. As shown in Fig. 3, the iron particles follow this relationship closely in all three samples with different spacer layer thicknesses. This trend suggests the presence of assemblies of noninteracting magnetic particles with uniaxial anisotropy on the basis of Néel's concept of superparamagnetism. However, in a dense systems, such as in the present study (volume fraction of nanoparticles $=0.43$ for $6 \mathrm{~nm}$ $\mathrm{Al}_{2} \mathrm{O}_{3}, 0.33$ for $12 \mathrm{~nm} \mathrm{Al}_{2} \mathrm{O}_{3}$, and 0.26 for $18 \mathrm{~nm} \mathrm{Al}_{2} \mathrm{O}_{3}$ spacer layer samples), the interparticle interaction is known to modify the magnetic behavior of the assembly. ${ }^{7,17,18}$ The values of $T_{B}$ obtained from the fitting of the $H_{c}(T)$ data to

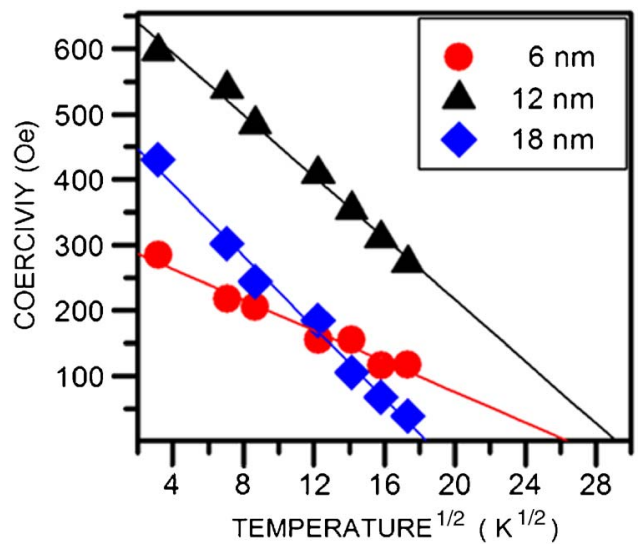

FIG. 3. (Color online) Coercivity as a function of temperature with the data fitted to equation $H_{c}=2 K / M_{s}\left[1-\left(T / T_{B}\right)^{1 / 2}\right]$. 
Eq. (1) are 690, 846, and $336 \mathrm{~K}$, respectively, for samples with 6,12 , and $18 \mathrm{~nm}$ thick $\mathrm{Al}_{2} \mathrm{O}_{3}$ spacer layers. The variation of $T_{B}$ for samples with the same particle size in a matrix with different spacer layer thicknesses can be explained using the concept of magnetic interactions in dispersed magnetic nanoparticle assemblies. ${ }^{17-20}$

Two types of interaction mechanisms-dipolar and exchange-can operate between nanoparticles depending on the interparticle distances and agglomeration. Since the matrix $\left(\mathrm{Al}_{2} \mathrm{O}_{3}\right)$ in the present study is insulating and nonmagnetic, the interaction among $\mathrm{Fe}$ nanoparticles is expected to be predominantly dipolar. However, if the spacer layer is very thin, it may not be able to separate the magnetic particles completely in one layer from magnetic particles in the next layer and so on over the entire macroscopic sample in a uniform fashion. As seen in Fig. 1(a), some of the Fe nanoparticles in one layer are indeed in direct contact with $\mathrm{Fe}$ particles in neighboring layers. When the magnetic particles are in contact with each other, the exchange type of interparticle interaction dominates where atomic spins within a particle are coupled. When the $\mathrm{Al}_{2} \mathrm{O}_{3}$ spacer layer thickness is increased to $12 \mathrm{~nm}$, the possibility of interlayer Fe particle contacts is greatly diminished which, in turn, promotes the dipolar interaction mechanism. The strength of dipolar interaction is determined by two parameters, namely, the average distance between the particles and their size. ${ }^{20,21}$ Since the particle size and interparticle separation in a given layer are fixed, it is reasonable to assume that magnetic interaction in the intralayer is the same in all the three samples. Therefore, an increase in $T_{B}$ of $12 \mathrm{~nm} \mathrm{Al}_{2} \mathrm{O}_{3}$ spacer layer sample by nearly $20 \%$ with respect to that of $10 \mathrm{~nm} \mathrm{Al}_{2} \mathrm{O}_{3}$ spacer layer sample can be attributed to change in interlayer interaction mechanism to dipolar type from exchange type. An increase in $T_{B}$ by a factor of up to 2 has been observed for magnetic nanoparticle dispersions with the same particle size but with a different volume fraction, which, in turn, affects the interactions among magnetic particles. ${ }^{17-20}$ The decrease in $T_{B}$ and $H_{c}$ with further increase in spacer layer thickness (i.e., at $18 \mathrm{~nm}$ ) can be explained by the decrease in the strength of interparticle dipolar strength. The dipolar interaction can be weak, moderate, or strong, depending on the level of volume fraction. $^{17-19}$

In summary, we have fabricated multilayered samples with fixed $\mathrm{Fe}$ nanoparticle size and variable spacer layer thickness using a physical vapor deposition based PLD process. The variation of coercivity values as a function of spacer layers indicates the existence of an optimum thickness of a spacer layer to realize strong magnetic dipolar interaction and, hence, to realize high values of coercivity at higher temperatures in a given system. The ability to change interlayer particle interaction without changing intralayer particle interaction by means of spacer layer thickness variation can provide a convenience means to study the physics of interactions among magnetic nanoparticles.

This work was supported by a NSF-NIRT under Grant No. DMR-0403480 and by the Center for Advanced Materials and Smart Structures.

${ }^{1}$ S. Sun, C. B. Murray, D. Weller, L. Folks, and A. Moser, Science 287, 1989 (2000).

${ }^{2}$ C. L. Chien, Annu. Rev. Mater. Sci. 25, 129 (1995).

${ }^{3}$ O. Santini, D. H. Mosca, W. H. Schreiner, R. Marangoni, J. L. Guimarães, F. Wypych, and A. J. A. de Oliveira, J. Phys. D 36, 428 (2003).

${ }^{4} J$. S. Moodera, L. R. Kindler, T. M. Wong, and R. Meservey, Phys. Rev. Lett. 74, 3273 (1995).

${ }^{5}$ V. Russier, C. Petit, J. Legrand, and M. P. Pileni, Phys. Rev. B 62, 3910 (2000).

${ }^{6}$ Y. Lalatonne, L. Motte, V. Russier, A. T. Ngo, P. Bonville, and M. P. Pileni, J. Phys. Chem. B 108, 1848 (2004).

${ }^{7}$ D. Farrel, Y. Cheng, R. W. Mccallum, M. Achan, and S. A. Majetich, J. Phys. Chem. B 109, 13409 (2005).

${ }^{8}$ X. M. Lin, C. M. Sorensen, K. J. Klabunde, and G. C. Hadjipanayis, Langmuir 14, 7140 (1998).

${ }^{9}$ C. P. Collier, J. O. Jeppesen, Y. Luo, J. Perkins, E. W. Wong, J. R. Heath, and J. F. Stoddart, J. Am. Chem. Soc. 123, 12632 (2001).

${ }^{10}$ T. Cui, F. Hua, and Y. Lvov, IEEE Trans. Electron Devices 51, 503 (2004).

${ }^{11}$ C. Joachim, J. K. Gimzewski, and A. Aviram, Nature (London) 408, 541 (2000).

${ }^{12}$ M. Ollsen, B. Persson, and L. Salford, Magn. Reson. Imaging 4, 437 (1986).

${ }^{13}$ D. Kumar, J. Narayan, A. V. Kvit, A. K. Sharma, and J. Sankar, J. Magn. Magn. Mater. 232, 161 (2001).

${ }^{14}$ D. Kumar, A. Lupini, S. J. Pennycook, J. Narayan, and G. Duscher, Appl. Phys. Lett. 81, 4204 (2002)

${ }^{15}$ R. K. Singh and D. Kumar, Mater. Sci. Eng., R. 22, 113 (1998).

${ }^{16}$ R. S. Williams and S. Chaudhury, in Chemistry of High Temperature Superconductors II, edited by D. L. Nelson and T. F. George (American Chemical Society, Los Angeles, CA, 1988), p. 291.

${ }^{17}$ D. Kechrakos and K. N. Trohidou, Phys. Rev. B 58, 12169 (1998).

${ }^{18}$ J. L. Dorman, L. Bessais, and D. Fiorani, J. Phys. C 21, 2015 (1988).

${ }^{19}$ S. Gangopadhyay, G. C. Hadjipanayis, C. M. Sorenson, and K. J. Klabunde, IEEE Trans. Magn. 29, 2619 (1993).

${ }^{20}$ R. W. Chantrell, M. El-Hilo, and K. O'Grady, IEEE Trans. Magn. 27, 3570 (1991)

${ }^{21}$ A. Ceylan, C. C. Baker, S. K. Hasanain, and S. Ismat Shah, Phys. Rev. B 72, 134411 (2005). 